\title{
Planning Optimization of the Work Processes of Gas Cleaning Facilities of a Power Plant by Means of Mathematical Processing and Computer Simulation
}

\author{
Olesya Aksenova ${ }^{1, *}$, and Evgenia Nikolaeva $^{1}$ \\ ${ }^{1}$ T.F. Gorbachev Kuzbass State Technical Univer sity, 650000, 28 Vesennyaya St., Kemerovo, Russia
}

\begin{abstract}
The article seeks to examine the efficiency of applying means of mathematical processing and computer modeling of the work processes of gas cleaning facilities of power plants to optimize the process of planning and designing of future power plant in operation. A way of solution of the gas outbursts cleaning problem at the stage of designing measures for the development of waste processing systems through mathematical processing of expected volumes of gas outbursts and computer simulation of individual pieces of equipment and working areas as a whole is offered. The authors present the results of the processing of the projected technological processes and the gas outbursts cleaning facilities in terms of E-networks and using mathematical processing in the application Simulink, which allows to build a model of the device and to carry out calculations on the screen using the library of building blocks. A 3D model of the gas cleaning facilities, which allows to visualize the technological process and to compare it with theoretical calculations at the design stage of the future power plant and, if necessary, make changes to the project, has been created by means of computer modeling.
\end{abstract}

\section{Introduction}

At present, the electric power industry is the most important basic industry of Russia. The level of its development affects the entire national economy, as well as the level of development of scientific and technological progress in the country.

It is practically impossible to imagine modern life without electric energy. The electric power industry has invaded all spheres of human activity: industry and agriculture, science and space, and our everyday life. In industrial applications, electric power is used both for activating various mechanisms and in technological processes directly.

Major electricity producers include hydroelectric power plants, nuclear power plants and thermal power plants. Thermal power plants (TPPs) require special attention. There are about 700 large and medium-sized thermal power plants in Russia. They produce up to $70 \%$ of electricity. TPPs use organic fuel - coal, oil, gas, fuel oil, shale oil, peat.

\footnotetext{
${ }^{*}$ Corresponding author: olesya_aksenova42@mail.ru
} 


\section{Materials and Methods}

At the stage of planning the processes of fuel and energy facilities and the development of technical documentation, a modern range of computer programs enables to present an analysis of the future TPP operation in different ways. Mathematical modeling [1-3] makes it possible to verify the correctness of the model and its correction at the stage of construction, three-dimensional computer simulation allows to get a realistic image based on the available technical documentation, to identify technical errors and make adjustments at the planning stage of individual technological processes and thermal power plants as a whole.

During the mathematical analysis it is advisable to use the E-network device [4-6]. As an extension of Petri nets, E-nets are a graphical and mathematical tool used to model systems of different types.

The paper studies an abstracted model of thermal power plants with the possibility of expansion (Fig.1.).

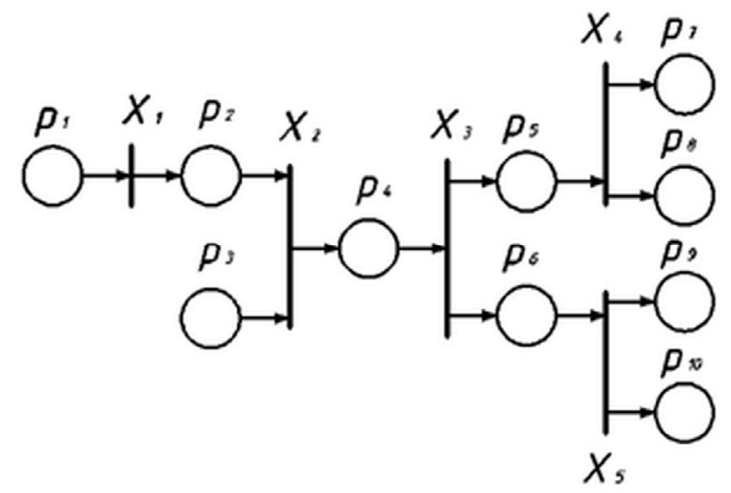

Fig. 1. The model CHP in terms of E-nets.

where $\mathrm{p}_{1}-\mathrm{a}$ new portion of coal entered the crusher station;

$\mathrm{p}_{2}$ - coal is processed;

$\mathrm{p}_{3}$ - condensate and replenished water loss are at the storage facility;

$\mathrm{p}_{4}$ - the raw material is in the furnace chamber;

$\mathrm{p}_{5}$ - combustion products are obtained;

$\mathrm{p}_{6}$ - steam is supplied to the turbine;

$\mathrm{p}_{7}$ - bottom ash waste is transported to the recycling system;

$\mathrm{p}_{8}-$ gaseous wastes enter the cleaning system;

$\mathrm{p}_{9}$ - power is allocated to external consumers;

$\mathrm{p}_{10}$ - steam from the extraction turbine is supplied to CHP;

$\mathrm{X}_{1}=\left(\mathrm{T}, 0, \varphi_{1}\right)-$ the process of coal processing;

$$
\varphi_{1}=\mathrm{L}\left(\mathrm{X}_{1}\right)=\left\{\mathrm{p}_{1} \mathrm{X}_{1} \mid \mathrm{X}_{1} \rightarrow \mathrm{p}_{1} \mathrm{p}_{2}\right\}=\left\{\mathrm{p}_{1} \mathrm{p}_{2}\right\} ;
$$

$\mathrm{X}_{2}=\left(\mathrm{I}, 0, \varphi_{2}\right)$ - loading of raw materials into the furnace chamber;

$$
\varphi_{2}=\mathrm{L}\left(\mathrm{X}_{2}\right)=\left\{\mathrm{p}_{2} \mathrm{p}_{3} \mathrm{X}_{2} \mid \mathrm{X}_{2} \rightarrow \mathrm{p}_{2} \mathrm{p}_{3} \mathrm{p}_{4}\right\}=>L\left(\mathrm{X}_{2}\right)=\left\{\mathrm{p}_{2} \mathrm{p}_{3} \mathrm{p}_{4}\right\} ;
$$

$\mathrm{X}_{3}=\left(\mathrm{F}, 0, \varphi_{3}\right)-$ processing of raw materials;

$\mathrm{X}_{4}=\left(\mathrm{F}, 0, \varphi_{4}\right)$-waste withdrawal;

$$
\varphi_{3}=\mathrm{L}\left(\mathrm{X}_{3}\right)=\left\{\mathrm{p}_{4} \mathrm{X}_{3} \mid \mathrm{X}_{3} \rightarrow \mathrm{p}_{4} \mathrm{p}_{5} \mathrm{p}_{6}\right\}=\left\{\mathrm{p}_{4} \mathrm{p}_{5} \mathrm{p}_{6}\right\}
$$

$$
\varphi_{4}=\mathrm{L}\left(\mathrm{X}_{4}\right)=\left\{\mathrm{p}_{5} \mathrm{X}_{4} \mid \mathrm{X}_{4} \rightarrow \mathrm{p}_{5} \mathrm{p}_{7} \mathrm{p}_{8}\right\}=\left\{\mathrm{p}_{5} \mathrm{p}_{7} \mathrm{p}_{8}\right\} ;
$$

$\mathrm{X}_{5}=\left(\mathrm{F}, 0, \varphi_{5}\right)-$ electricity generation and steam removal; 
$\varphi_{5}=\mathrm{L}\left(\mathrm{X}_{5}\right)=\left\{\mathrm{p}_{6} \mathrm{X}_{5} \mid \mathrm{X}_{5} \rightarrow \mathrm{p}_{6} \mathrm{p}_{9} \mathrm{p}_{10}\right\}=\left\{\mathrm{p}_{6} \mathrm{p}_{9} \mathrm{p}_{10}\right\}$, the initial marking is represented by a vector: $(1,0,1,0,0,0,0,0,0,0)$.

To implement the computer-built model of the E-network the technical computing application program package MatLab was used, namely, its application - Simulink.

\section{Results and Discussion}

The model created in Simulink is a balance model of material flows [6,7], consisting of several technological stages: coal losses during its preparation for combustion; generation of electricity; formation and processing of bottom ash waste; formation and cleaning of gas outbursts. For the sake of clarity of the balance model and the convenience of its expansion, processing and cleaning units were implemented in the form of subsystems. Let us consider the subsystem of cleaning gas outbursts TPP, which in turn also consists of several modules: an electric filter, carbon capture, a system of purification from nitrogen oxides and a system of desulphurization.

Sulfur oxides, as well as its acids have a negative impact on human health, are the cause of forest destruction, acidification of water bodies and corrosion of metal structures. To date, there are more than 80 ways to extract sulfur oxides from flue gases. Let us consider a wet desulfurization method in which gypsum is produced as the final product. The scheme of the wet desulfurization method is shown in figure 2 .

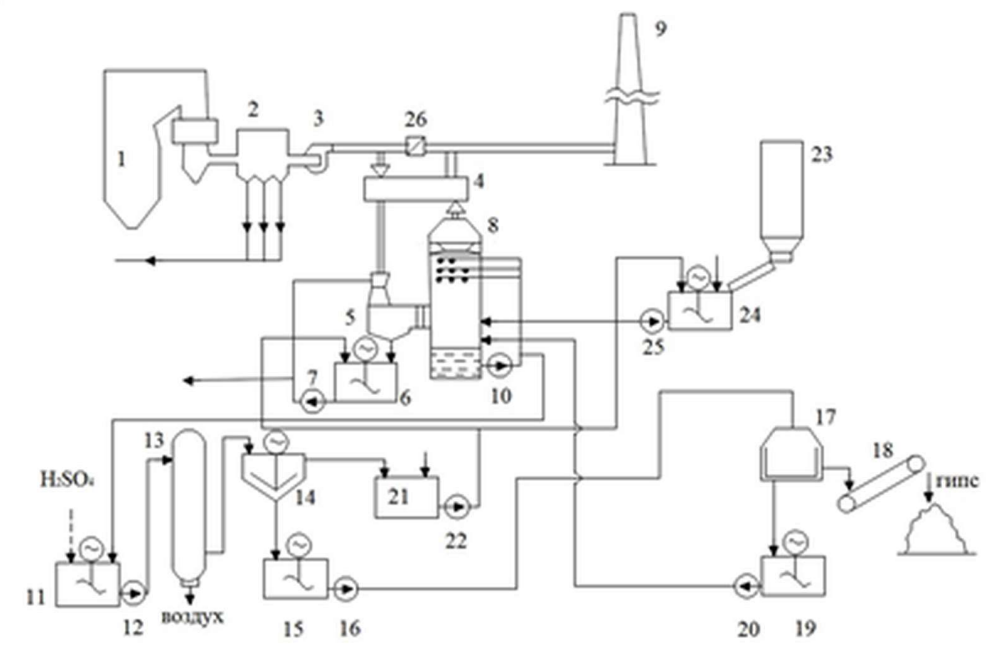

Fig. 2. Scheme of the method of wet desulfurization.

Where 1 - boiler; 2 - electrostatic precipitator; 3 - smoke exhauster; 4 - regenerative gas heater; 5 - scrubber in gear; 6 - circulating capacity of the scrubber; $7,10,12,16,20,22$, 25 - pumps; 8 - absorber; 9 -stack; 11 - oxidative tank; 13 - oxidation tower; 14 - thickener; 15 - thickener tank; 17 - centrifuges; 18 -conveyor; 19 - centrifuges tanks; 21 - clarified water container; 23 - limestone container; 24 - container for slurry; 26 - switching the gate.; 26 -switching damper.

Model of this system in terms of E-networks is presented in Fig. 3 with the following symbols:

$\mathrm{p}_{1}$ - flue gases are fed to the heat exchanger;

$\mathrm{p}_{2}$ - flue gases enter Venturi scrubber;

$\mathrm{p}_{3}$ - water for scrubber operation is supplied from the scrubber recirculation tank; 
$\mathrm{p}_{4}$ - part of ash pulp is removed from the system;

$\mathrm{p}_{5}$ - flue gases enter the absorber;

$\mathrm{p}_{6}$ - limestone is fed into the tank for making slurry;

$\mathrm{p}_{7}$ - ready slurry enters the absorber;

$\mathrm{p}_{8}$ - purified gas passes heat exchanger;

$\mathrm{p}_{9}$ - purified gas leaves the installation through the smoke exhauster;

$\mathrm{p}_{10}$ - reaction products are collected in the circulation tanks;

$p_{11}$ - washing solution again enters into reaction;

$\mathrm{p}_{12}$ - part of the pulp enters the oxidative tank;

$\mathrm{p}_{13}$ - sulfuric acid is fed to the oxidative tank;

$\mathrm{p}_{14}$ - calcium sulfite is pumped to the oxidation tower;

$\mathrm{p}_{15}$ - pulp enters the thickener;

$\mathrm{p}_{16}$ - concentrated calcium sulfate is sent to the centrifuges.

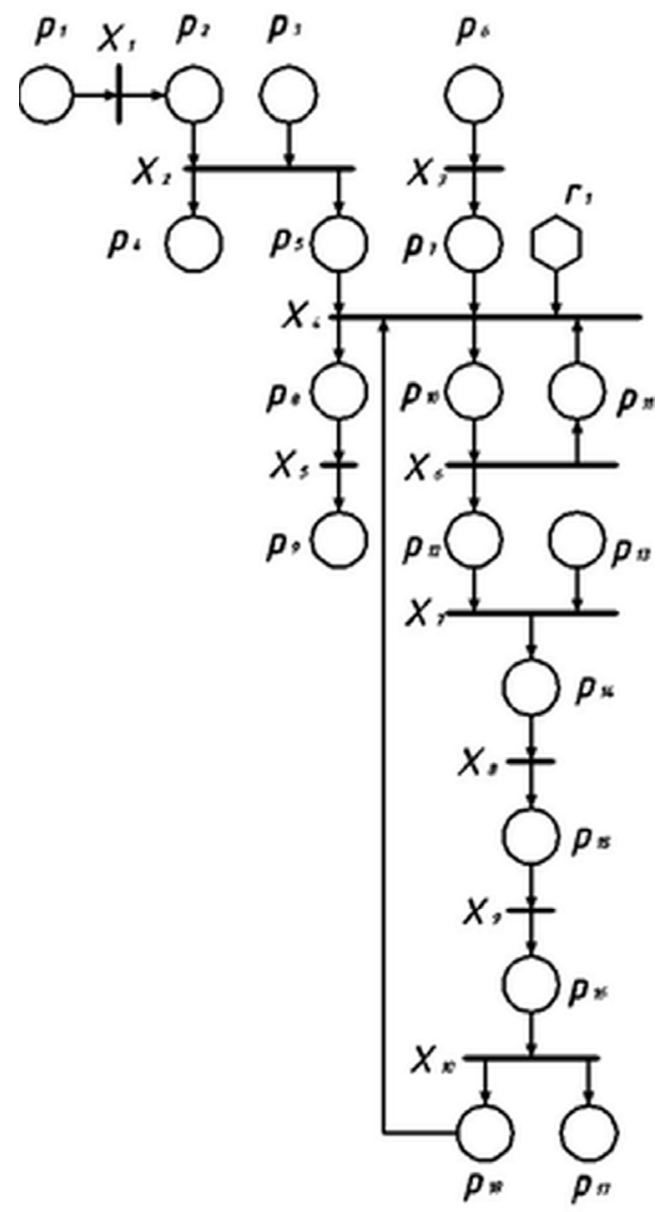

Fig. 3. Model of sulfur oxide capture system in terms of E-nets.

Where $\mathrm{X}_{1}=\left(\mathrm{T}, 0, \varphi_{1}\right)-$ the process of cooling the flue gases; 


$$
\begin{aligned}
& \varphi_{1}=\mathrm{L}\left(\mathrm{X}_{1}\right)=\left\{\mathrm{p}_{1} \mathrm{X}_{1} \mid \mathrm{X}_{1} \rightarrow \mathrm{p}_{1} \mathrm{p}_{2}\right\}=\left\{\mathrm{p}_{1} \mathrm{p}_{2}\right\} \\
& \mathrm{X}_{2}=\left(\mathrm{I}, 0, \varphi_{2}\right) \text { - cooling the gases to a saturation temperature; } \\
& \varphi_{2}=L\left(X_{2}\right)=\left\{p_{2} p_{3} X_{2} \mid X_{2} \rightarrow p_{2} p_{3} p_{4} p_{5}\right\}=>L\left(X_{2}\right)=\left\{p_{2} p_{3} p_{4} p_{5}\right\} ; \\
& \mathrm{X}_{3}=\left(\mathrm{T}, 0, \varphi_{3}\right) \text { - preparation of the slurry to the absorber; } \\
& \varphi_{3}=\mathrm{L}\left(\mathrm{X}_{3}\right)=\left\{\mathrm{p}_{6} \mathrm{X}_{3} \mid \mathrm{X}_{3} \rightarrow \mathrm{p}_{6} \mathrm{p}_{7}\right\}=\left\{\mathrm{p}_{6} \mathrm{p}_{7}\right\} ; \\
& \mathrm{X}_{4}=\left(\mathrm{Y}, 0, \varphi_{4}\right)-\text { the process of purification from sulfur oxides; } \\
& \varphi_{4}=\mathrm{L}\left(\mathrm{X}_{4}\right) \\
& =\left\{\begin{array}{c}
\mathrm{p}_{5} \rightarrow \mathrm{X}_{4}, \mathrm{p}_{7} \rightarrow \mathrm{X}_{4}, \mathrm{p}_{11} \rightarrow \mathrm{X}_{4}, \mathrm{p}_{18} \rightarrow \mathrm{X}_{4}, \mathrm{r}_{1} \rightarrow \mathrm{X}_{4}, \mathrm{X}_{4} \rightarrow \mathrm{p}_{8}, \mathrm{X}_{4} \rightarrow \mathrm{p}_{10}<=>\mathrm{r}_{1}=0 \mathrm{v} \\
\mathrm{p}_{5} \rightarrow \mathrm{X}_{4}, \mathrm{p}_{7} \rightarrow \mathrm{X}_{4}, \mathrm{p}_{11} \rightarrow \mathrm{X}_{4}, \mathrm{p}_{18} \rightarrow \mathrm{X}_{4}, \mathrm{r}_{1} \rightarrow \mathrm{X}_{4}, \mathrm{X}_{4} \rightarrow \mathrm{p}_{8}, \mathrm{X}_{4} \rightarrow \mathrm{p}_{10}<=>\mathrm{r}_{1}=1 \mathrm{~V}
\end{array}\right. \\
& \left.\begin{array}{l}
\vee\left(p_{5}=1, p_{7}=1, p_{11}=0, p_{18}=0, p_{8}=0, p_{10}=0\right) \rightarrow p_{5} p_{7} p_{8} p_{10} \\
\left(p_{5}=1, p_{7}=1, p_{11}=1, p_{18}=1, p_{8}=0, p_{10}=0\right) \rightarrow p_{5} p_{7} p_{8} p_{10} p_{11} p_{18}
\end{array}\right\}=>L\left(X_{4}\right) \\
& =\left\{p_{5} p_{7} p_{8} p_{10} \wedge p_{5} p_{7} p_{8} p_{10} p_{11} p_{18}\right\} \\
& \mathrm{X}_{5}=\left(\mathrm{T}, 0, \varphi_{5}\right)-\text { the heat exchange process; } \\
& \varphi_{5}=\mathrm{L}\left(\mathrm{X}_{5}\right)=\left\{\mathrm{p}_{8} \mathrm{X}_{5} \mid \mathrm{X}_{5} \rightarrow \mathrm{p}_{8} \mathrm{p}_{9}\right\}=\left\{\mathrm{p}_{8} \mathrm{p}_{9}\right\} \text {; } \\
& \mathrm{X}_{6}=\left(\mathrm{F}, 0, \varphi_{6}\right)-\text { the separation process; } \\
& \varphi_{6}=\mathrm{L}\left(\mathrm{X}_{6}\right)=\left\{\mathrm{p}_{10} \mathrm{X}_{6} \mid \mathrm{X}_{6} \rightarrow \mathrm{p}_{10} \mathrm{p}_{11} \mathrm{p}_{12}\right\}=\left\{\mathrm{p}_{10} \mathrm{p}_{11} \mathrm{p}_{12}\right\} \text {; } \\
& \mathrm{X}_{7}=\left(\mathrm{I}, 0, \varphi_{7}\right) \text { - oxidation of calcium carbonate residues; } \\
& \varphi_{7}=\mathrm{L}\left(\mathrm{X}_{7}\right)=\left\{\mathrm{p}_{12} \mathrm{p}_{13} \mathrm{X}_{7} \mid \mathrm{X}_{7} \rightarrow \mathrm{p}_{12} \mathrm{p}_{13} \mathrm{p}_{14}\right\}=>L\left(\mathrm{X}_{2}\right)=\left\{\mathrm{p}_{12} \mathrm{p}_{13} \mathrm{p}_{14}\right\} \text {; } \\
& \mathrm{X}_{8}=\left(\mathrm{T}, 0, \varphi_{8}\right) \text { - final oxidation of calcium sulfite with oxygen; } \\
& \varphi_{8}=\mathrm{L}\left(\mathrm{X}_{8}\right)=\left\{\mathrm{p}_{14} \mathrm{X}_{8} \mid \mathrm{X}_{8} \rightarrow \mathrm{p}_{14} \mathrm{p}_{15}\right\}=\left\{\mathrm{p}_{14} \mathrm{p}_{15}\right\} \text {; } \\
& \mathrm{X}_{9}=\left(\mathrm{T}, 0, \varphi_{9}\right)-\text { dehydration of calcium sulfate; } \\
& \varphi_{9}=\mathrm{L}\left(\mathrm{X}_{9}\right)=\left\{\mathrm{p}_{15} \mathrm{X}_{9} \mid \mathrm{X}_{9} \rightarrow \mathrm{p}_{15} \mathrm{p}_{16}\right\}=\left\{\mathrm{p}_{15} \mathrm{p}_{16}\right\} \text {; } \\
& \mathrm{X}_{10}=\left(\mathrm{F}, 0, \varphi_{10}\right)-\text { the process of separating gypsum from water; } \\
& \varphi_{10}=\mathrm{L}\left(\mathrm{X}_{2}\right)=\left\{\mathrm{p}_{16} \mathrm{X}_{10} \mid \mathrm{X}_{10} \rightarrow \mathrm{p}_{16} \mathrm{p}_{17} \mathrm{p}_{18}\right\}=\left\{\mathrm{p}_{16} \mathrm{p}_{17} \mathrm{p}_{18}\right\} \text {; } \\
& \mathrm{r}_{1} \text {-presence testing of water and slurry in the absorber. }
\end{aligned}
$$

The desulphurization system at the TPP, implemented in the application, Simulink, is presented in Fig. 4.

For realistic representation of the cleaning system of gas outbursts from oxides of sulfur and more exact calculation of the area planned under the equipment, on the basis of the available technical documentation solid models of the equipment and pipelines are constructed in several graphic editors. Then, taking into account the planned project area and the arrangement of the equipment the three-dimensional image of the future technological line and industrial process is realized. This image allows you to see the technical flaws in the theoretical planning and eliminate them.
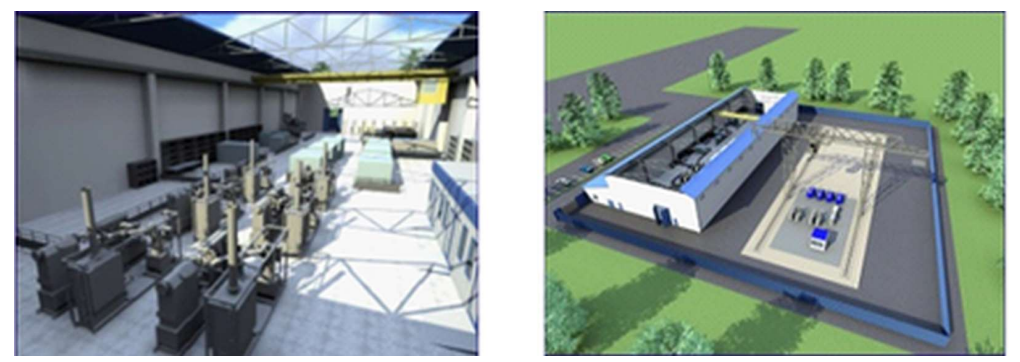

Fig. 4. Three-dimensional model of sulfur oxides capture and storage system.

In the same way it is possible to analyze all the modules of the cleaning gas outbursts subsystem for TPP. In particular, the formula below was used to calculate the indicators of the sulfur oxide capture system module: 


$$
\mathrm{M}_{\mathrm{SO}_{2}}=0,02 \cdot \mathrm{m} \cdot \mathrm{S} \cdot\left(1-\eta_{\mathrm{SO}_{2}}^{1}\right) \cdot\left(1-\eta_{\mathrm{SO}_{2}}^{2}\right)
$$

where $\mathrm{M}_{\mathrm{SO}_{2}}$ - gross emissions of sulfur oxides calculated as sulfur dioxide;

$\mathrm{S}-$ sulphur content in \%;

$\eta_{\mathrm{SO}_{2}}^{1}$ - proportion of sulphur oxides bound by fly ash;

$\eta_{\mathrm{SO}_{2}}^{2}$ - proportion of sulphur oxides captured in the ash catcher.

A number of substances (in tons) generated in the processing of 18,000 tons of coal is the following: particulate matter $-0,5837$; carbon dioxide $-105,4$; nitric oxide $-0,01684$; oxides of sulfur- 1,782; crude gold and silver $(<10 \%)-0,00001818$; aluminum sulphate coagulant - 2764; uranium - 6,48; thorium 0,1163 ; tantalum, niobium, cerium, yttrium 32,4 ; titanium oxide $-170,5$; retentate of zirconium with a hafnium - 1494; gallium 0,02479; liquid glass - 3161; electricity (in MW/h) - 112540,06.

In conclusion, it should be noted that the resulting model can be further expanded by adding the necessary modules to its structure.

\section{Conclusions}

The problem of the use of mathematical processing and computer simulation while planning the working processes of the gas cleaning facilities of a power plant at the stage of planning and design of TPP has been considered in the paper. Optimization of gas outbursts cleaning system planning by means of mathematical processing and computer simulation has been proposed, which can make it possible to evaluate the planned performance, select the production technology, as well as to ensure a high environmental effect of the planned waste treatment system. The paper presents the results of processing of the planned technological processes and gas outbursts cleaning system in terms of E-networks with the use of mathematical processing in the application Simulink, a three-dimensional model of the gas outbursts system has been built, which allows to visualize the process and compare with theoretical calculations at the design stage of a TPP and, if necessary, make changes.

\section{References}

1. S. A. Muhsin, Radiotekhnika, 155, 159 (2008)

2. O. Aksenova, E. Nikolaeva, M. Cehlár, E3S Web of Conferences, 21, 03009 (2017)

3. S. P. Bakhaeva, V. A. Gogolin, I. A. Ermakova, Journal of Mining Science, 52:3, 454 (2016)

4. G. A. Kazunina, D. V. Alekseev, Advanced Materials Research, 933, 62 (2014)

5. A. Kovalchuk, M. Klopot, Energetika: ekonomika, tekhnologiï, ekologiya, 3:37, 97 (2014)

6. Morad Behandish, T. Horea, Computer-Aided Design, 70, 100 (2016)

7. Ba Wenlan, Ning Ren Lixin, Graphical Models, 82, 1 (2015)

8. Hao Yang, Hui Zhang, Computers \& Graphics, 65, 45 (2017)

9. V. M. Zolotukhin, V.A. Gogolin, M. Yu. Yazevich, M.I. Baumgarten, A.V. Dyagileva, IOP Conference Series: Earth and Environmental Science, 50:1 (2017) 